\title{
Prevention of post-endoscopic retrograde cholangiopancreatography pancreatitis with rectal non-steroidal anti-inflammatory drugs
}

\author{
Tae Young Park ${ }^{1}$, Hyoung-Chul Oh${ }^{2}$, Evan L. Fogel ${ }^{3}$, and Glen A. Lehman ${ }^{3}$
}

${ }^{1}$ Department of Internal Medicine, Inje University Seoul Paik Hospital, Seoul; ${ }^{2}$ Division of Gastroenterology, Chung-Ang University College of Medicine, Seoul, Korea; ${ }^{3}$ Division of Gastroenterology and Hepatology, Indiana University School of Medicine, Indianapolis, IN, USA
Received: February 24, 2020 Accepted: March 25, 2020

\section{Correspondence to} Hyoung-Chul Oh, M.D. Division of Gastroenterology, Chung-Ang University College of Medicine, 102 Heukseok-ro, Dongjak-gu, Seoul o6973, Korea Tel: $+82-2-6299-3149$ Fax: +82-2-6299-3119 E-mail: ohcgi@cau.ac.kr https://orcid.org/0000-0003oo68-5030

Acute pancreatitis is the most common and feared adverse event associated with performance of endoscopic retrograde cholangiopancreatography (ERCP). Unremitting effort has been made for over 40 years to minimize the frequency and severity of this complication. Recently, the use of rectal non-steroidal anti-inflammatory drugs (NSAIDs) have opened a new era for its prevention. This review focuses on the role of NSAIDs in pancreatitis, the pharmacokinetics of these agents, and summarizes the results of clinical trials with rectal NSAIDs alone and combination regimens in the prevention of post-ERCP pancreatitis.

Keywords: Cholangiopancreatography, endoscopic retrograde; Pancreatitis; Anti-inflammatory agents, non-steroidal

\section{INTRODUCTION}

Acute pancreatitis is the most common and arguably most feared adverse event related with endoscopic retrograde cholangiopancreatography (ERCP) $[1,2]$. The frequency of post-ERCP pancreatitis (PEP) has been reported to be $3.4 \%$ to $6.0 \%$ in average-risk groups $[3,4]$ and $8 \%$ to $13.1 \%$ in high-risk groups $[4,5]$, resulting in significant morbidity and mortality $[6,7]$.

Since 1977, when clinical trials using aprotinin [8] and calcitonin [9] were reported, more than 35 pharmacologic agents have been evaluated for the prevention of $\mathrm{PEP}$, with several different mechanisms of action. However, most of those pharmacologic agents have shown no consistent benefit or questionable efficacy for PEP prevention.
Recently, rectally administered non-steroidal anti-inflammatory drugs (NSAIDs; indomethacin and diclofenac) were determined to be potentially effective in the prevention of PEP in both low- and high-risk patients [10-13] and ultimately a landmark trial in high-risk patients showed a $46 \%$ relative risk (RR) reduction of PEP with rectally administered indomethacin [5]. However, the preventive effect of rectal NSAIDs on PEP is suboptimal since PEP continues to occur with rectal NSAIDs in certain patients. Therefore, novel trials with a combination of rectal NSAIDs and other pharmacologic agents have been conducted.

In this review, the role of NSAIDs in pancreatitis, pharmacokinetics of rectal NSAIDs, and results of clinical trials with rectal NSAIDs alone and 
combination regimens in PEP prevention will be reviewed and summarized.

\section{PATHOPHYSIOLOGY OF PEP}

The causes of PEP are multi-factorial. Both patientand procedure-related factors induce various inciting events that may cause mechanical obstruction from edematous trauma of the pancreatic sphincter, increase pancreatic ductal pressure or stimulate spasm of the sphincter of Oddi. These inciting events finally lead to a common vicious inflammatory cycle of inappropriate activation of pancreatic enzymes and auto-digestion [14].

\section{ROLE OF NSAIDs IN PANCREATITIS}

An inducible form of cyclooxygenase-2 (COX-2) has been implicated as an important proinflammatory mediator [15]. COX-2 is up-regulated in response to a variety of pro-inflammatory stimuli including interleukin 1 , tumor necrosis factor $\alpha$, and bacterial lipopolysaccharide [16-18]. COX-2 mRNA and protein levels are increased during experimental pancreatitis [19]. Inhibition of COX-2 by either pharmacologic inhibition or selective genetic deletion markedly attenuated the severity of acute pancreatitis in animal models, suggesting that COX-2 plays as an important pro-inflammatory regulator of the severity of pancreatitis [19].

The hypothetical mechanism of COX-2 inhibition in ameliorating experimental pancreatitis may involve two distinct pathways [20]. The direct effect of COX-2 inhibition is the reduction in prostaglandin synthesis, which promotes edema formation and vascular changes, in pancreas and serum [21-23]. COX-2 inhibition may also suppress the activation of transcription factor nuclear factor $\kappa \mathrm{B}(\mathrm{NF}-\kappa \mathrm{B})$, which plays an important role in proinflammatory cytokine expression [22,24]. However, some experimental studies failed to demonstrate inhibition of the NF- $\mathrm{BB}$ activation with the COX2 inhibitor (celecoxib) [22]. Two human case-control studies evaluated the association with oral COX-2 inhibitors and other NSAIDs including diclofenac and indomethacin $[25,26]$. The adjusted odds ratios (ORs) for acute pancreatitis were 1.4 (95\% confidence interval [CI],
1.0 to 2.0 ) to 5.62 (95\% CI, 3.33 to 9.45) for current COX2 selective inhibitor (celecoxib), and 3.6 (95\% CI, 3.33 to 9.45) for indomethacin and 5.0 (95\% CI, 3.33 to 9.45) for diclofenac, respectively, compared with controls. These data suggest that the cumulative or simultaneous use of COX-2 inhibitors and NSAIDs may increase the risk of acute pancreatitis.

\section{WHY ONLY RECTAL NSAIDs ARE EFFECTIVE FOR PEP}

Indomethacin and diclofenac follow linear pharmacokinetics. Plasma concentration and area under the curve are proportional to the dose administered, whereas half-life ( $\mathrm{T}$ 1/2) and plasma and renal clearance are not dose-dependent. Indomethacin and diclofenac are both rapidly absorbed from the gastrointestinal tract and following oral administration have virtually $90 \%$ to $100 \%$ bioavailability, with peak plasma concentrations following a single dose occurring between one and 1.5 hours in the fasting state [27-29]. In contrast, peak plasma concentration of indomethacin occurred 40 minutes after intramuscular injection and 60 minutes after rectal suppository. The bioavailability after rectal suppository was about $80 \%$ [30,31].

Oral (two doses given 6 hours apart) $[32,33]$ and intramuscular administration [34] of diclofenac have not shown a protective effect on PEP. Why are these methods of administration not effective in PEP prevention when the bioavailability is more than $90 \%$ in both instances? Diclofenac undergoes first-pass metabolism (a phenomenon of drug metabolism whereby the concentration of a drug is greatly reduced before it reaches the systemic circulation) with only $50 \%$ to $60 \%$ of the drug reaching the systemic circulation as intact diclofenac [29,35]. In contrast, as indomethacin is not subject to significant first-pass metabolism, oral indomethacin potentially may exert a preventive effect on PEP.

What is the specific mechanism by which rectal indomethacin demonstrates its preventive effect on PEP? Peak plasma concentration is achieved in 90 minutes after rectal indomethacin, but this peak plasma concentration is sustained for more than 2 hours and decreases slowly, compared to intravascular and intramuscular administration (Fig. 1) [31]. Based on the previous 


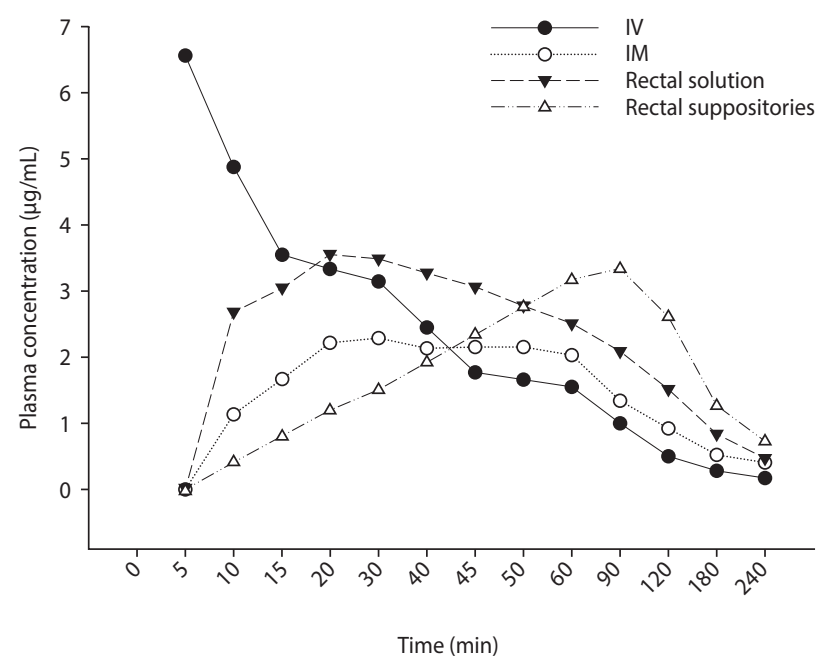

Figure 1. Plasma concentration profile of indomethacin in eight human subjects following four different administrations. Adapted from Jensen et al. [31], with permission from John Wiley and Sons. IV, intravenous; IM, intramuscular.

reports that have demonstrated a consistent beneficial effect of rectal indomethacin on the prevention of PEP, this sustained plasma concentration may play a key role in the prevention of PEP. The correlation between its preventive effect and high sustained plasma concentration needs to be further evaluated by measuring the plasma concentration at various time points after rectal indomethacin in clinical practice. Potentially, the veiled hypothetical mechanism for prevention of PEP may be further elucidated. Furthermore, these pharmacokinetic data may guide the design of new studies with indomethacin and PEP prevention.

\section{ADMINISTRATION AND TIMING OF RECTAL NSAIDs}

Rectal NSAIDs have been administered at different time points in previous clinical trials according to the optimal pharmacokinetics of rectal NSAIDs assumed by the individual researchers, varying from 5 hours before ERCP to immediately after ERCP.

In two meta-analyses, the optimal timing of administration of rectal NSAIDs was evaluated [36,37]. The first meta-analysis showed that rectal NSAIDs administered before ERCP lowered the risk of PEP with statistical significance (RR, $0.48 ; 95 \% \mathrm{CI}, 0.29$ to $0.78 ; p=0.003$ )
[36]. In contrast, the second meta-analysis showed the efficacy of rectal indomethacin or diclofenac for PEP prevention did not differ whether the NSAIDs were administered before or after ERCP (RR, 0.54; 95\% CI, 0.42 to $0.70 ; p=0.99)$ [37].

In a recent trial of 162 patients, double dose rectal indomethacin (200 mg) was administered as $100 \mathrm{mg}$ at 4.5 hours before and $100 \mathrm{mg}$ immediately after ERCP and compared with a single $100 \mathrm{mg}$ dose given immediately after ERCP [38]. In the 42 patients deemed to be at high risk for pancreatitis, there was no significant reduction in PEP with the double dose (single dose 9.5\%, $\mathrm{n}=2$; double dose $4.8 \%, \mathrm{n}=1 ; \mathrm{p}=0.24$ ).

Considering the peak plasma concentration of indomethacin is 90 minutes after rectal administration, and no benefit of early administration (i.e., 4 hours) pre-ER$\mathrm{CP}$, we believe that the optimal timing for rectal NSAID administration might be 90 minutes before starting the ERCP, but further study is warranted.

\section{OVERALL PROPHYLACTIC EFFECT}

The frequency of PEP before the widespread administration of rectal NSAIDs (in 2012) was reported to be $9.7 \%$ (95\% CI, $8.6 \%$ to $10.7 \%$ ) in a meta-analysis of randomized placebo-controlled trials (RCT) [7]. The frequency of PEP among 10,591 patients from 94 non-risk stratified RCTs was 8.5\% (95\% CI, 7.4\% to $9.5 \%$ ). In 22 RCTs (with 2,345 patients) where risk stratification was performed, the frequency of PEP in high-risk patients was $14.7 \%$ ( $95 \% \mathrm{CI}, 11.8 \%$ to $17.7 \%$ ). In addition, the frequency of moderate and severe PEP in the high-risk subgroup was reported to be $3.9 \%$ (95\% CI, $2.6 \%$ to $5.3 \%$ ) and $0.8 \%$ (95\% CI, $0.3 \%$ to $1.2 \%$ ), respectively.

In an analysis of 24 prospective RCTs using rectal NSAIDs for PEP prevention, the frequency of PEP among 7,798 patients who were administered with rectal NSAIDs was 6.3\% (95\% CI, 5.7\% to 6.8\%) (unpublished extracted data). The frequency of PEP among 5,431 average-risk patients from 17 RCTs was $5.7 \%$ (95\% CI, 5.1\% to 6.3\%). The frequency of PEP among 1,661 highrisk patients from seven RCTs was 7.2\% (95\% CI, 5.9\% to $8.4 \%$ ). Among all 7,798 patients, the rate of moderate-to-severe PEP was 1.3\% (95\% CI, 1.0\% to 1.5\%) (Table 1). Rectal NSAIDs significantly reduced the frequency 
Table 1. Trend in the frequency of post-ERCP pancreatitis

\begin{tabular}{lcc}
\hline Variable & $\begin{array}{c}\text { Before widespread administration of } \\
\text { rectal NSAIDs }\end{array}$ & $\begin{array}{c}\text { 24 Randomized controlled trials using } \\
\text { rectal NSAIDs }\end{array}$ \\
\hline Total no. of patients & 13,296 & 7,798 \\
Frequency of PEP, \% & 9.7 & 6.3 \\
Non-risk stratified (average-risk) group & 8.5 & 5.7 \\
High-risk group & 14.7 & 7.2 \\
Moderate-to-severe PEP, \% & $4.7^{\mathrm{a}}$ & $1.3^{\mathrm{b}}$ \\
\hline
\end{tabular}

ERCP, endoscopic retrograde cholangiopancreatography; NSAID, non-steroidal anti-inflammatory drug; PEP, post-endoscopic retrograde cholangiopancreatography pancreatitis.

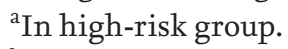

${ }^{\mathrm{b}}$ Among all 7,798 patients.

of PEP with a RR of 0.53 (95\% CI, 0.44 to $0.63 ; p<0.001$ ) according to a meta-analysis of 21 RCTs with 6,134 patients [39].

\section{PROPHYLACTIC EFFECT ACCORDING TO RISK STRATIFICATION}

Although the prophylactic effect of rectal indomethacin on PEP was seen in high-risk patients in a landmark study [5], controversies in prophylactic effect remain as to whether the same benefit is seen across patient risk stratification. Specially, are rectal NSAIDs indicated for PEP prophylaxis in low-risk patients?

In an RCT of 449 consecutive patients, a single 100 mg dose of rectal indomethacin during ERCP did not prevent PEP. However, approximately $70 \%$ of the enrolled patients were at average risk for developing PEP [40]. Pancreatitis occurred in 16 of 223 patients (7.2\%) in the indomethacin group and 11 of $226(4.9 \%)$ in the placebo group $(p=0.33)$. In contrast, a retrospective cohort study of 4,017 patients, including low-risk patients (mostly those with malignant biliary obstruction), showed that post-procedural rectal indomethacin administration was associated with a significant decrease in the absolute rate and severity of PEP [3]. The overall frequency of PEP was reduced from $4.7 \%$ to $2.0 \%$ (OR, $0.35 ; 95 \% \mathrm{CI}, 0.24$ to $0.51 ; p<0.001)$ and moderate-to-severe PEP from $2.7 \%$ to $0.6 \%$ (OR, 0.17; 95\% CI, 0.09 to $0.32 ; p<0.001)$.

Two meta-analyses have addressed the question whether there is a difference in prevention of PEP with rectal NSAIDs when evaluating average-risk and high-risk patients [37,41]. In one meta-analysis, rectal indomethacin was found to be protective against PEP in high-risk patients ( $\mathrm{RR}, 0.43 ; 95 \% \mathrm{CI}, 0.28$ to 0.65 ; $p<0.001)$ but not average-risk patients $(\mathrm{RR}, 0.74 ; 95 \%$ CI, 0.52 to $1.07 ; p=0.115$ ) [41]. The other meta-analysis showed that the efficacy of diclofenac or indomethacin was significant both in the high-risk group (RR, 0.53; 95\% CI, 0.29 to $0.97 ; p=0.038)$ and the average-risk group (RR, 0.63; 95\% CI, 0.46 to $0.86 ; p=0.003$ ). The difference between the high-risk and average-risk patients was not significant $(p=0.69)$. The number needed to treat was 13 in the high-risk group and 27 in the average-risk group [37].

\section{DOSE OF RECTAL NSAIDS: LOW VS. SINGLE VS. DOUBLE DOSE}

The majority of published clinical trials to date have been conducted with a single $100 \mathrm{mg}$ dose of rectal indomethacin or diclofenac.

A trial from Japan evaluated the efficacy of low-dose (50 $\mathrm{mg}$ ) rectal diclofenac [42]. The frequency of PEP was significantly lower with the low-dose rectal diclofenac than the control group (3.9\% [2/51] vs. $18.9 \%$ [10/53], $p=$ 0.017 ). In this trial, dose reduction to $25 \mathrm{mg}$ was performed in patients weighing $<50 \mathrm{~kg}$. There was no significant difference in the frequency of PEP between the 25 and $50 \mathrm{mg}$ groups as well (9\% [2/22] vs. ०\% [0/29], p $=0.101$ ). Considering a lower mean body weight of this Japanese population, low-dose $50 \mathrm{mg}$ of rectal NSAID 
Table 2. Summary of randomized controlled trials

\begin{tabular}{lcc}
\hline Regimens & No. of RCTs & Results \\
\hline NSAIDs alone & 2 & Not efficacious \\
Oral & 2 & Not efficacious \\
Intravenous & 4 & Efficacious in 2 of 4 RCTs \\
Intramuscular & $14 / 2$ & Efficacious, but no additional \\
Rectal, single/double dose & & benefit with double dose \\
Combination regimens & & Efficacious \\
Rectal diclofenac + IV somatostatin & 1 & Efficacious \\
Rectal indomethacin + IV hydration & 3 & Not efficacious in 2 of 3 RCTs \\
Rectal indomethacin + intraduodenal epinephrine spray & 3 & Efficacious \\
\hline Rectal NSAIDs + sublingual nitrate & 2 & \\
\hline
\end{tabular}

RCT, randomized controlled trial; NSAID, non-steroidal anti-inflammatory drug; IV, intravenous.

may be effective for PEP prevention in similar patient populations.

Recently, two randomized clinical trials with dose escalation of rectal indomethacin to $200 \mathrm{mg}$ were reported $[38,43]$. It was hypothesized that a higher dose might be superior to the existing standard $100 \mathrm{mg}$ dose in PEP prevention. Split dose administration was performed in both studies: to minimize the potential for adverse events of the higher dose in one study [38], and to potentially lead to a higher peak serum concentration and a more sustained impact on the inflammatory cascade in the second study [43]. In the first trial from Taiwan, which evaluated predominantly average-risk patients, the double dose group received an initial 100 mg about 4 to 5 hours before ERCP and an additional $100 \mathrm{mg}$ immediately after ERCP [38]. In the second trial, a multicenter trial from USA which evaluated only patients who were considered to be at high-risk for the development of PEP, the high-dose group received an initial $150 \mathrm{mg}$ at the end of the ERCP, followed by an additional $50 \mathrm{mg} 4$ hours after the procedure [43]. In both studies, dose escalation of rectal indomethacin to $200 \mathrm{mg}$ did not confer any additional reduction in PEP.

\section{COMBINATION WITH OTHER PHARMACOLOGICAL AGENTS}

Administration of a rectal NSAID at ERCP has led to a significant reduction in frequency and severity of PEP, particularly in high-risk patients. While this discovery has been a major breakthrough in ERCP, PEP remains a significant concern, and cases of severe PEP continue to occur, albeit at a reduced rate. Clearly, the only foolproof method to prevent PEP is to not proceed with the procedure. Additional study is needed to further lower PEP rates. In addition to studies evaluating a higher dose of the NSAID (i.e., double dose) as described above $[38,43]$, trials with combination rectal NSAIDS and other strategies or pharmacologic agents including intravenous fluids [44-46], intravenous somatostatin [47], sublingual isosorbide dinitrate $[48,49]$, and intraduodenal epinephrine spray [50-52] have been reported (Table 2).

One trial evaluated the preventive efficacy for PEP with the combination of rectal diclofenac and intravenous somatostatin [47]. With this combination, the frequency of PEP significantly decreased compared with placebo (12/255 [4.7\%] vs. 27/260 [10.4\%], $p=0.015)$. This benefit was confined to those patients considered to be at high-risk for PEP (11/188 [5.8\%] vs. 25/203 [12.3\%], $p=0.027)$, with no benefit noted in the low-risk group $(1 / 67[1.5 \%]$ vs. $2 / 57$ [3.5\%], $p=0.594)$. While it would be of interest to know the PEP rates of patients who received either diclofenac or somatostatin (but not both) in this patient population, in order to better assess the efficacy of the combination therapy, no patient received single drug therapy in this study.

There were three trials that evaluated with combi- 
nation of rectal NSAIDs and aggressive intravenous hydration of normal saline [44] and lactated Ringer's solution $[45,46]$. Three trials consistently showed that the frequency of PEP was significantly lower with the combination of rectal NSAIDs and aggressive hydration compared with placebo (o\% to $6 \%$ vs. $2.7 \%$ to $21 \%$ ).

Two clinical trials evaluated the preventive efficacy for PEP with the combination of rectal NSAIDs and sublingual isosorbide dinitrate $[48,49]$. Both trials showed that the frequency of PEP was significantly lower with the combination therapy compared with rectal NSAIDs alone (6.7\% vs. $15.3 \%$ [48] and 5.6\% vs. 9.5\% [49]).

Three clinical trials were conducted with the combination of rectal indomethacin and topical epinephrine sprayed on the major papilla, based on the results of a previous network meta-analysis [50-53]. In the first trial, the frequency of PEP was significantly lower with the combination regimen compared with rectal indomethacin alone (0\% vs. 9\%) [50]. However, in the subsequent two large-scale trials, the frequency of PEP with the combination regimen was not significantly different compared with rectal indomethacin alone $(6.7 \%$ to $8.5 \%$ vs. $5.3 \%$ to $6.4 \%)[51,52]$. Overall, there does not appear to be any additional benefit to epinephrine spray with reduction in $\mathrm{PEP}$ in patients receiving rectal indometh$\operatorname{acin}[54]$.

\section{ADDITIONAL PANCREATIC DUCT STENT}

Several randomized, controlled trials and meta-analyses have proven a significant reduction in frequency and severity of PEP with prophylactic pancreatic duct stent placement [55,56]. However, indomethacin significantly reduced the risk of PEP regardless of pancreatic duct stent placement (among patients with a pancreatic stent, from $16.1 \%$ to $9.7 \%$; patients without a pancreatic stent, from $20.6 \%$ to $6.3 \%$ ) [5]. In addition, a network meta-analysis has shown that rectal NSAIDs alone are superior to pancreatic duct stents in preventing PEP with a pooled odd ratio of 0.48 (95\% CI, 0.26 to 0.87 ) [57].

Considering the increased technical demands of pancreatic duct stent placement (familiarity with smaller caliber guidewires, ansa pancreatica anatomy, etc.) even when performed by experienced endoscopists, further study is needed to clarify whether additional pancreatic duct stent placement may be recommended in certain situations (e.g., unintentional cannulation of the pancreatic duct in biliary cases). An ongoing clinical trial will clarify the additional prophylactic role of a pancreatic duct stent in high-risk patients [58].

\section{SUGGESTED RECOMMENDATIONS}

Current literature clearly demonstrates a reduction in PEP with rectal NSAIDs in high-risk patients, with a benefit in average- or low-risk patients less clear. However, given the relatively low cost, ease of administration and safety profile of rectal NSAIDs, it is reasonable to administer rectal NSAIDs to all patients undergoing ERCP. Furthermore, aggressive intravenous fluid administration should be provided. An additional second (or third) agent such as sublingual nitrate or intravenous somatostatin could be considered for high-risk patients.

\section{CONCLUSIONS}

Rectal NSAIDs have definitely opened a new era for the prevention of PEP. However, further studies to decrease its incidence and to attenuate the severity are warranted.

\section{Conflict of interest}

No potential conflict of interest relevant to this article was reported.

\section{REFERENCES}

1. Freeman ML, Nelson DB, Sherman S, et al. Complications of endoscopic biliary sphincterotomy. N Engl J Med 1996;335:909-918.

2. Freeman ML, Guda NM. Prevention of post-ERCP pancreatitis: a comprehensive review. Gastrointest Endosc 2004;59:845-864.

3. Thiruvengadam NR, Forde KA, Ma GK, et al. Rectal indomethacin reduces pancreatitis in high- and low-risk patients undergoing endoscopic retrograde cholangiopancreatography. Gastroenterology 2016;151:288-297. 
4. Luo H, Zhao L, Leung J, et al. Routine pre-procedural rectal indometacin versus selective post-procedural rectal indometacin to prevent pancreatitis in patients undergoing endoscopic retrograde cholangiopancreatography: a multicentre, single-blinded, randomised controlled trial. Lancet 2016;387:2293-2301.

5. Elmunzer BJ, Scheiman JM, Lehman GA, et al. A randomized trial of rectal indomethacin to prevent post-ERCP pancreatitis. N Engl J Med 2012;366:1414-1422.

6. Andriulli A, Loperfido S, Napolitano G, et al. Incidence rates of post-ERCP complications: a systematic survey of prospective studies. Am J Gastroenterol 2007;102:17811788.

7. Kochar B, Akshintala VS, Afghani E, et al. Incidence, severity, and mortality of post-ERCP pancreatitis: a systematic review by using randomized, controlled trials. Gastrointest Endosc 2015;81:143-149.

8. Brust R, Thomson AB, Wensel RH, Sherbaniuk RW, Costopoulos L. Pancreatic injury following ERCP. Failure of prophylactic benefit of Trasylol. Gastrointest Endosc 1977;24:77-79.

9. Odes HS, Novis BN, Barbezat GO, Bank S. Effect of calcitonin on the serum amylase levels after endoscopic retrograde cholangiopancreatography. Digestion 1977;16:180184.

10. Murray B, Carter R, Imrie C, Evans S, O'Suilleabhain C. Diclofenac reduces the incidence of acute pancreatitis after endoscopic retrograde cholangiopancreatography. Gastroenterology 2003;124:1786-1791.

11. Sotoudehmanesh R, Khatibian M, Kolahdoozan S, Ainechi S, Malboosbaf R, Nouraie M. Indomethacin may reduce the incidence and severity of acute pancreatitis after ERCP. Am J Gastroenterol 2007;102:978-983.

12. Montano Loza A, Rodriguez Lomeli X, Garcia Correa JE, et al. Efecto de la administracion de indometacina rectal sobre los niveles sericos de amilasa posteriores a colangiopancreatografía retrograda endoscopica y su impacto en la aparicion de episodios de pancreatitis secundaria [Effect of the administration of rectal indomethacin on amylase serum levels after endoscopic retrograde cholangiopancreatography, and its impact on the development of secondary pancreatitis episodes]. Rev Esp Enferm Dig 2007;99:330-336.

13. Khoshbaten M, Khorram H, Madad L, Ehsani Ardakani MJ, Farzin H, Zali MR. Role of diclofenac in reducing post-endoscopic retrograde cholangiopancreatogra- phy pancreatitis. J Gastroenterol Hepatol 2008;23(7 Pt 2):e11-e16.

14. Murray WR. Reducing the incidence and severity of post ERCP pancreatitis. Scand J Surg 2005;94:112-116.

15. Hla T, Neilson K. Human cyclooxygenase-2 cDNA. Proc Natl Acad Sci U S A 1992;89:7384-7388.

16. Agro A, Langdon C, Smith F, Richards CD. Prostaglandin E2 enhances interleukin 8 (IL-8) and IL-6 but inhibits GMCSF production by IL-1 stimulated human synovial fibroblasts in vitro. J Rheumatol 1996;23:862-868.

17. Crofford LJ, Wilder RL, Ristimaki AP, et al. Cyclooxygenase-1 and -2 expression in rheumatoid synovial tissues: effects of interleukin-1 beta, phorbol ester, and corticosteroids. J Clin Invest 1994;93:1095-1101.

18. Huang ZF, Massey JB, Via DP. Differential regulation of cyclooxygenase-2 (COX-2) mRNA stability by interleukin-1 beta (IL-1 beta) and tumor necrosis factor-alpha (TNF-alpha) in human in vitro differentiated macrophages. Biochem Pharmacol 2000;59:187-194.

19. Ethridge RT, Chung DH, Slogoff M, et al. Cyclooxygenase-2 gene disruption attenuates the severity of acute pancreatitis and pancreatitis-associated lung injury. Gastroenterology 2002;123:1311-1322.

20. Chan YC, Leung PS. Acute pancreatitis: animal models and recent advances in basic research. Pancreas 2007;34:1-14.

21. Masferrer JL, Zweifel BS, Manning PT, et al. Selective inhibition of inducible cyclooxygenase 2 in vivo is antiinflammatory and nonulcerogenic. Proc Natl Acad Sci U S A 1994;91:3228-3232.

22. Song AM, Bhagat L, Singh VP, Van Acker GG, Steer ML, Saluja AK. Inhibition of cyclooxygenase-2 ameliorates the severity of pancreatitis and associated lung injury. Am J Physiol Gastrointest Liver Physiol 2002;283:G1166-G1174.

23. Foitzik T, Hotz HG, Hotz B, Wittig F, Buhr HJ. Selective inhibition of cyclooxygenase-2 (COX-2) reduces prostaglandin E2 production and attenuates systemic disease sequelae in experimental pancreatitis. Hepatogastroenterology 2003;50:1159-1162.

24. Slogoff MI, Ethridge RT, Rajaraman S, Evers BM. COX2 inhibition results in alterations in nuclear factor (NF)-kappaB activation but not cytokine production in acute pancreatitis. J Gastrointest Surg 2004;8:511-519.

25. Sorensen HT, Jacobsen J, Norgaard M, Pedersen L, Johnsen SP, Baron JA. Newer cyclo-oxygenase-2 selective inhibitors, other non-steroidal anti-inflammatory drugs and the risk of acute pancreatitis. Aliment Pharmacol 
Ther 2006;24:111-116.

26. Hung SC, Hung SR, Lin CL, Lai SW, Hung HC. Use of celecoxib correlates with increased relative risk of acute pancreatitis: a case-control study in Taiwan. Am J Gastroenterol 2015;110:1490-1496.

27. Lucas S. The pharmacology of indomethacin. Headache 2016;56:436-446.

28. Turakka H, Airaksinen MM. Biopharmaceutical assessment of phenylbutazone and indomethacin preparations. Ann Clin Res 1974;6 Suppl 11:34-43.

29. Riess W, Stierlin H, Degen $P$, et al. Pharmacokinetics and metabolism of the anti-inflammatory agent Voltaren. Scand J Rheumatol Suppl 1978;22:17-29.

30. Wallusch WW, Nowak H, Leopold G, Netter KJ. Comparative bioavailability: influence of various diets on the bioavailability of indomethacin. Int J Clin Pharmacol Biopharm 1978;16:40-44.

31. Jensen KM, Grenabo L. Bioavailability of indomethacin after intramuscular injection and rectal administration of solution and suppositories. Acta Pharmacol Toxicol (Copenh) 1985:57:322-327.

32. Cheon YK, Cho KB, Watkins JL, et al. Efficacy of diclofenac in the prevention of post-ERCP pancreatitis in predominantly high-risk patients: a randomized double-blind prospective trial. Gastrointest Endosc 2007;66:1126-1132.

33. Lee TY, Choi JS, Oh HC, Song TJ, Do JH, Cheon YK. Oral udenafil and aceclofenac for the prevention of post-endoscopic retrograde cholangiopancreatography pancreatitis in high-risk patients: a randomized multicenter study. Korean J Intern Med 2015;30:602-609.

34. Park SW, Chung MJ, Oh TG, et al. Intramuscular diclofenac for the prevention of post-ERCP pancreatitis: a randomized trial. Endoscopy 2015;47:33-39.

35. Willis JV, Kendall MJ, Flinn RM, Thornhill DP, Welling PG. The pharmacokinetics of diclofenac sodium following intravenous and oral administration. Eur J Clin Pharmacol 1979;16:405-410.

36. Rustagi T, Njei B. Factors affecting the efficacy of nonsteroidal anti-inflammatory drugs in preventing post-endoscopic retrograde cholangiopancreatography pancreatitis: a systematic review and meta-analysis. Pancreas 2015;44:859-867.

37. Patai A, Solymosi N, Mohacsi L, Patai AV. Indomethacin and diclofenac in the prevention of post-ERCP pancreatitis: a systematic review and meta-analysis of prospective controlled trials. Gastrointest Endosc 2017;85:1144-1156.

38. Lai JH, Hung CY, Chu $\mathrm{CH}$, et al. A randomized trial comparing the efficacy of single-dose and double-dose administration of rectal indomethacin in preventing post-endoscopic retrograde cholangiopancreatography pancreatitis. Medicine (Baltimore) 2019;98:e15742.

39. Lyu Y, Cheng Y, Wang B, Xu Y, Du W. What is impact of nonsteroidal anti-inflammatory drugs in the prevention of post-endoscopic retrograde cholangiopancreatography pancreatitis: a meta-analysis of randomized controlled trials. BMC Gastroenterol 2018;18:106.

40. Levenick JM, Gordon SR, Fadden LL, et al. Rectal indomethacin does not prevent post-ERCP pancreatitis in consecutive patients. Gastroenterology 2016;150:911-917.

41. Inamdar S, Han D, Passi M, Sejpal DV, Trindade AJ. Rectal indomethacin is protective against post-ERCP pancreatitis in high-risk patients but not average-risk patients: a systematic review and meta-analysis. Gastrointest Endosc 2017;85:67-75.

42. Otsuka T, Kawazoe S, Nakashita S, et al. Low-dose rectal diclofenac for prevention of post-endoscopic retrograde cholangiopancreatography pancreatitis: a randomized controlled trial. J Gastroenterol 2012;47:912-917.

43. Fogel EL, Lehman GA, Tarnasky P, et al. Rectal indometacin dose escalation for prevention of pancreatitis after endoscopic retrograde cholangiopancreatography in high-risk patients: a double-blind, randomised controlled trial. Lancet Gastroenterol Hepatol 2020;5:132-141.

44. Hosseini M, Shalchiantabrizi P, Yektaroudy K, Dadgarmoghaddam M, Salari M. Prophylactic effect of rectal indomethacin administration, with and without intravenous hydration, on development of endoscopic retrograde cholangiopancreatography pancreatitis episodes: a randomized clinical trial. Arch Iran Med 2016;19:538-543.

45. Mok SRS, Ho HC, Shah P, Patel M, Gaughan JP, Elfant AB. Lactated Ringer's solution in combination with rectal indomethacin for prevention of post-ERCP pancreatitis and readmission: a prospective randomized, double-blinded, placebo-controlled trial. Gastrointest Endosc 2017;85:1005-1013.

46. Hajalikhani M, Emami MH, Khodadoostan M, Shavakhi A, Rezaei M, Soluki R. Combination of diclofenac and aggressive hydration for the prevention of post-ERCP pancreatitis. Gastroenterol Hepatol Bed Bench 2018;11:319324.

47. Katsinelos P, Fasoulas K, Paroutoglou G, et al. Combina- 
tion of diclofenac plus somatostatin in the prevention of post-ERCP pancreatitis: a randomized, double-blind, placebo-controlled trial. Endoscopy 2012;44:53-59.

48. Sotoudehmanesh R, Eloubeidi MA, Asgari AA, Farsinejad $M$, Khatibian M. A randomized trial of rectal indomethacin and sublingual nitrates to prevent post-ERCP pancreatitis. Am J Gastroenterol 2014;109:903-909.

49. Tomoda T, Kato H, Ueki T, et al. Combination of diclofenac and sublingual nitrates is superior to diclofenac alone in preventing pancreatitis after endoscopic retrograde cholangiopancreatography. Gastroenterology 2019;156:1753-1760.

50. Hatami B, Kashfi SMH, Abbasinazari M, et al. Epinephrine in the prevention of post-endoscopic retrograde cholangiopancreatography pancreatitis: a preliminary study. Case Rep Gastroenterol 2018;12:125-136.

51. Kamal A, Akshintala VS, Talukdar R, et al. A randomized trial of topical epinephrine and rectal indomethacin for preventing post-endoscopic retrograde cholangiopancreatography pancreatitis in high-risk patients. Am J Gastroenterol 2019;114:339-347.

52. Luo H, Wang $X$, Zhang R, et al. Rectal indomethacin and spraying of duodenal papilla with epinephrine increases risk of pancreatitis following endoscopic retrograde cholangiopancreatography. Clin Gastroenterol Hepatol 2019;17:1597-1606.
53. Akshintala VS, Hutfless SM, Colantuoni E, et al. Systematic review with network meta-analysis: pharmacological prophylaxis against post-ERCP pancreatitis. Aliment Pharmacol Ther 2013;38:1325-1337.

54. Gromski MA, Fogel EL. End of the road for epinephrine spraying of the papilla to prevent post-endoscopic retrograde cholangiopancreatography pancreatitis? Clin Gastroenterol Hepatol 2019;17:1446-1447.

55. Choudhary A, Bechtold ML, Arif M, et al. Pancreatic stents for prophylaxis against post-ERCP pancreatitis: a meta-analysis and systematic review. Gastrointest Endosc 2011;73:275-282.

56. Mazaki T, Mado K, Masuda H, Shiono M. Prophylactic pancreatic stent placement and post-ERCP pancreatitis: an updated meta-analysis. J Gastroenterol 2014;49:343-355.

57. Akbar A, Abu Dayyeh BK, Baron TH, Wang Z, Altayar O, Murad MH. Rectal nonsteroidal anti-inflammatory drugs are superior to pancreatic duct stents in preventing pancreatitis after endoscopic retrograde cholangiopancreatography: a network meta-analysis. Clin Gastroenterol Hepatol 2013;11:778-783.

58. Elmunzer BJ, Serrano J, Chak A, et al. Rectal indomethacin alone versus indomethacin and prophylactic pancreatic stent placement for preventing pancreatitis after ERCP: study protocol for a randomized controlled trial. Trials 2016;17:120. 